studies that might consume a higher proportion of future funding.

\section{Conclusion}

The future health of mental health research in England depends on ensuring that the potential benefits of rationalisation and centralisation are realised and the pitfalls avoided.

\section{Declaration of interest}

The author is a recipient of research grants, including grants from NHS R\&D.

\section{References}

ALBERTI, K. G. (2000) Multicentre research ethics committees: has the cure been worse than the disease? No, but idiosyncracies and obstructions to good must be removed. BMJ, 320, 1157-1158.

DEPARTMENT OF HEALTH (2004) Research Governance in Health and Social Care - NHS Permission for R\&D Involving NHS Patients. London: Department of Health. http:// www.dh.gov.uk/assetRoot/04/07/ 58/22/04075822.doc

DEPARTMENT OF HEALTH (2005) Report of the Ad Hoc Advisory Group on the Operation of NHS Research
Ethics Committees. London: Department of Health

EUROPEAN PARLIAMENTAND COUNCIL (2001) Directive 2001/20/EC. Luxembourg: European Parliament and Council.

NATIONAL PATIENT SAFETY AGENCY

(2005) Standard Operating Procedures for Research Ethics Committees. London: Central Office for Research Ethics Committees. http:www.corec. org.uk/recs/index.htm

WALD, D. S. (2004) Bureaucracy of ethics applications. BMJ, 329, $282-284$ House, 21 Mansell Street, London E1 8AA, e-mail: plelliott@cru.rcpsych.ac.uk

\title{
The ground is in great shape, but can we field a kitted-out team? Commentary on ... Mental health research system in England ${ }^{\dagger}$
}

Chilvers \& Clark make it clear that research and development (R\&D) in the National Health Service (NHS) is now a managed process. There is a coherent strategy and much thought has been given to the use of resources. I welcome this development and the 'Health Research System' that forms its framework.

Mental health R\&D now has its own voice and leadership within this system, and the benefits are already evident. Especially noteworthy are initiatives such as the Mental Health Topic Working Group and the Strategic Review of Mental Health R\&D and their recommendations, and the consolidation of the UK Mental Health Research Network (UK MHRN; originally established via the National Institute for Mental Health in England; NIMHE). The UK MHRN provides a much needed national infrastructure for studies on a scale which is scientifically necessary, and has in its brief existence already adopted over 20 clinical trials.

The creation in 2004 of the UK Clinical Research Collaboration is another notable step. It brings together in partnership with the NHS, the key stakeholders - the main funding bodies, academic medicine, patients, industry, and even the National Institute for Clinical Excellence - to reinforce the position of the UK as a world leader in clinical research.

Chilvers \& Clark recognise that all of this is 'only a beginning' but it is one of which they can be proud.

There are, however, two issues, both alluded to in the paper, which are troubling and on which I would like to expand.

\section{Funding for mental health research}

The government has announced extra investment in R\&D, including mental health, and this has seen an expansion of the UK MHRN. The Medical Research Council (MRC) has funded 57 projects (out of 642 applications) under its $f 9$ million 'Brain Sciences Initiative', supplemented by f1 million from the Department of Health to pump prime further research in mental health. Around half of the MRC-funded projects are directly related to mental disorders. The establishment of a Mental Health Funders Forum, assuming a commitment from them to cooperate and succeed, should lead to a more coordinated approach to research funding. These are all positive developments.

However, will the funding of mental health research ever reach a level commensurate with the $12 \%$ of the global burden of disease (around 20\% in Europe) imposed by mental disorders (World Health Organization, 2001)? Perhaps it approximates the global figure for the NHS R\&D spend (total of $f 540$ million for 2003/4) - the Clarke Report in 2002 stated it was around $11 \%$. On my calculations the total NHS R\&D spend is just $0.8 \%$ of the total NHS budget, far below the $1.5 \%$ to which the first Director of R\&D aspired. Furthermore, most of this funding is tied up in services, with only a small proportion available for new projects. A service innovation can only be funded at the expense of an existing service. Sadly, there is no longer an element of 'responsive' (or
†See pp. 441-445 and $446-447$, this issue. opinion \& debate 
investigator-initiated) $R \& D$ funding, although there are hopes for a resurrection.

NHS R\&D generally funds smaller projects; large

opinion

\& debate trials, for instance, tend to be funded by the MRC or the Wellcome Trust. A recent review of MRC spending on mental health indicated that this stood at around 4.5\% (f18.9 million) in 2004 (Medical Research Council, 2004). (Compare this with the $\$ 1.8$ billion spent on mental health, around $6.5 \%$, for the National Institutes of Health in the US!) The fact that there is little charitable funding for mental health research, compared for example with cancer or heart disease, makes the situation even worse. Many studies in the mental health field involve complex interventions, outcome measures and designs, which may reduce their competitiveness against applications from other specialties. An end-point of 'dead' versus 'alive' is easier to assess than 'relapse' or 'quality of life'.

Industry, especially big pharmaceutical companies, is a potential source of major funding. However, such funding is often sensitive and may be viewed with suspicion, especially by psychiatric patients. Academe is often ambivalent about industry funding, a situation that might be improved if there were agreed processes (such as registration of all trials and transparent reporting) which could alleviate concerns about bias.

It is thus far from clear from where the funds will come to capitalise on the most welcome investments in infrastructure.

\section{The parlous state of academic medicine}

I am sure few readers of the Bulletin are aware of the recent dramatic reduction in the numbers of clinical academic staff (Council of Heads of Medical Schools, 2004). Between 2000 and 2004 there was a 12\% reduction in clinical academic consultants. For clinical lecturers, the decline was $42 \%$. The decline in some specialties has been greater than in others. Psychiatry is one of the worst hit. The number of clinical academics in 2004 was $77 \%$ of that in 2000; the number of clinical lecturers was only $35 \%$. These reductions have occurred in the face of four new medical schools and an increase in medical student numbers by $40 \%$. In the same period, the number of NHS consultants has risen by $25 \%$. Around $40 \%$ of academic posts are NHS funded.

The reasons for this decline are not difficult to understand - tensions between ever more rigorously stipulated responsibilities for clinical service, research and teaching; prolonged and inflexible training; a lack of funding for junior academic posts; poorly defined career pathways; and significant financial disincentives. Service and clinical governance demands seem always to be increasing whereas at the same time the Research Assessment Exercise - the basis for government funding for university departments and thus their survival - has made equal demands on research performance for clinical and non-clinical academics. Non-clinical academics are cheaper and generally produce more output. However, critically, they are poorly equipped for the key roles of teaching medical students, providing clinical scientist role models, and of translating research from the laboratory to the clinic. This is especially unfortunate at a time when new research approaches (for example, in genetics, neuroimaging, epidemiology, and clinical trials) promise so much for improvements in patient care.

The Academy of Medical Sciences (2002) and the Academic Careers Subcomittee of Modernising Medical Careers and the UK Clinical Research Collaboration (National Health Service, 2005) have published recommendations for change which tackle the problems outlined above. Colleagues might think about the implications of the demise of academic psychiatry the next time they are party to a debate about service needs versus research or teaching.

\section{Declaration of interest}

None.

\section{References}

ACADEMY OF MEDICAL SCIENCES (2002) Clinical Academic Medicine in Jeopardy: Recommendations for change. http://www.acmedsci.ac.uk/ f_pubs.htm

CLARKE, M. (2002) Clarke Report: Strategic Review Sub Group. London: Department of Health.

COUNCIL OF HEADS OF MEDICAL SCHOOLS (2004) A Survey of Clinical Academic Staffing Levels in UK Medical and Dental Schools. http:// www.chms.ac.uk/fchms_pubs.html

NATIONAL HEALTH SERVICE (2005) Report of the Academic Careers Sub-Committee of Modernising Medical Careers and the UK Clinical Research Collaboration. http:// www.mmc.nhs.uk/pages/academic WORLD HEALTH ORGANIZATION (2001) The World Health Report 2001: Mental Health: New Understanding, New Hope. Geneva: World Health Organization.
MEDICAL RESEARCH COUNCIL (2004) Mental Health Scoping Study. London: MRC.

George Szmukler Dean, Institute of Psychiatry, King's College London, De Crespigny Park, London SE5 8AF, e-mail: g.szmukler@iop.kcl.ac.uk 